\title{
QTL detection for Aeromonas salmonicida resistance related traits in turbot (Scophthalmus maximus)
}

\author{
Silvia T Rodríguez-Ramilo", Miguel A Toro², Carmen Bouza ${ }^{3}$, Miguel Hermida ${ }^{3}$, Belén G Pardo ${ }^{3}$, Santiago Cabaleiro ${ }^{4}$, \\ Paulino Martínez ${ }^{3}$ and Jesús Fernández ${ }^{5^{*}}$
}

\begin{abstract}
Background: Interactions between fish and pathogens, that may be harmless under natural conditions, often result in serious diseases in aquaculture systems. This is especially important due to the fact that the strains used in aquaculture are derived from wild strains that may not have had enough time to adapt to new disease pressures. The turbot is one of the most promising European aquaculture species. Furunculosis, caused by the bacterium Aeromonas salmonicida, produces important losses to turbot industry. An appealing solution is to achieve more robust broodstock, which can prevent or diminish the devastating effects of epizooties. Genomics strategies have been developed in turbot to look for candidate genes for resistance to furunculosis and a genetic map with appropriate density to screen for genomic associations has been also constructed. In the present study, a genome scan for QTL affecting resistance and survival to A. salmonicida in four turbot families was carried out. The objectives were to identify consistent QTL using different statistical approaches (linear regression and maximum likelihood) and to locate the tightest associated markers for their application in genetic breeding strategies.
\end{abstract}

Results: Significant QTL for resistance were identified by the linear regression method in three linkage groups (LGs 4, 6 and 9) and for survival in two LGs (6 and 9). The maximum likelihood methodology identified QTL in three LGs (5, 6 and 9) for both traits. Significant association between disease traits and genotypes was detected for several markers, some of them explaining up to $17 \%$ of the phenotypic variance. We also identified candidate genes located in the detected QTL using data from previously mapped markers.

Conclusions: Several regions controlling resistance to A. salmonicida in turbot have been detected. The observed concordance between different statistical methods at particular linkage groups gives consistency to our results. The detected associated markers could be useful for genetic breeding strategies. A finer mapping will be necessary at the detected QTL intervals to narrow associations and around the closely associated markers to look for candidate genes through comparative genomics or positional cloning strategies. The identification of associated variants at specific genes will be essential, together with the QTL associations detected in this study, for future marker assisted selection programs.

\section{Background}

In aquaculture, disease resistance related traits are of particular importance. The reason is that interactions between fish and pathogens, that may be harmless under natural conditions, often result in disease problems in aquaculture systems because of the added stress from

\footnotetext{
* Correspondence: jmj@inia.es

${ }^{5}$ Departamento de Mejora Genética Animal, Instituto Nacional de Investigación y Tecnología Agraria y Alimentaria, Ctra. A Coruña Km. 7.5, 28040 Madrid, Spain

Full list of author information is available at the end of the article
}

biological, physical and chemical factors [1]. This is especially important due to the fact that, in contrast to farm animals, the strains used in aquaculture usually have been very recently derived from wild strains [2] and, therefore, have had little time to adapt to the new disease pressures within the aquaculture environment.

Improvements in the performance of any productive or physiological characteristic of the cultured species can be achieved (if the trait is genetically determined) through artificial selection. Several breeding programmes have been developed for different traits in aquaculture species

\section{Ciomed Central}


usually involving growth rate, cold tolerance and disease resistance. However, implementing classical breeding programs focused on disease resistance traits could be highly problematic, since the phenotypic measurement of these traits is often complex and expensive. It is not possible to evaluate specimens to be selected and thus, evaluation has to be performed on relatives. Moreover, the required challenges may cause animal suffering and increase risks of infection at farm facilities [3]. Despite those disadvantages, some populations of Atlantic salmon have been already selected for resistance to bacterial and viral diseases. Selection for resistance to Infectious Pancreatic Necrosis (IPN) virus, based on bath challenge tests of several hundred families of first feeding fry, showed $66.6 \%$ and $29.3 \%$ mortality for low and high resistant strains, respectively [4]. Also, high resistance to IPN in rainbow trout was achieved by selective breeding [5]. In that study, the commercial strain RT-201 artificially challenged with IPN virus showed a mortality of $4.3 \%$, whereas the highly sensitive controls reached $96.1 \%$. In carps, Schäperclaus [6] found resistance to the dropsy disease, selected lines suffering low mortality (11.5\%) well below the unselected ones (57\%).

Positive response to selection pressures is possible because resistance against particular diseases affecting aquaculture species often shows moderate to high heritabilities and, thus, there is a large potential for genetic improvement. For example recent heritability estimates for resistance to Aeromonas salmonicida ranged from 0.43 to 0.62 in Atlantic salmon [reviewed by [7]], and it was $0.51 \pm 0.03$ in Salvelinus fontinalis [8].

Turbot (Scophthalmus maximus) is a flatfish that has been intensively cultured during the last decade due to its great commercial value. Its production in Europe has increased from $3000 \mathrm{Tm}$ in 1996 to $9246 \mathrm{Tm}$ in 2009 [9]. Increasing growth rate, controlling sex ratio (females largely outgrow males) and enhancing disease resistance currently constitute the main goals of genetic breeding programmes in this species. Pathologies constitute one of the main problems of turbot culture. Among these, furunculosis, caused by Aeromonas salmonicida, has produced important losses to turbot industry $[10,11]$. Genomic resources of turbot have increased in the last years $[12,13]$ and an immune-enriched oligo-microarray was designed and applied to identify candidate genes of resistance to A. salmonicida [14]. Also, a microsatellite consensus genetic map including centromere positions was reported in this species $[15,16]$, and recently, 31 EST-linked microsatellites, particularly useful for comparative genomics, were added to the consensus map [17]. Combining functional genomics strategies with the detection of genomic regions associated to productive characters (using genetic maps) increases the power to identify genes involved in the phenotypic differences occurring within and between families.

Besides an infinitesimal component (due to small effects of a huge number of loci) the variation in quantitative traits may be also controlled by a few genes with larger effects. Genomic regions closely linked to those genes show association with the trait phenotype and are known as quantitative trait loci (QTL) [18]. The effects of allele segregation at molecular markers throughout the genome can be used to determine the number and position of trait-related QTL, as well as the magnitude of their effects [19]. If, eventually, the responsible gene of a large effect on a trait is detected and the causal mutation determined, selection could be exerted directly on the genotype for that locus (Gene Assisted Selection, GAS). Alternatively, genetic maps provide DNA markers tightly linked to genes affecting different traits. Such markers can be used in Marker-Assisted Selection (MAS), selection based partly or fully on DNA marker genotypes. Consequently, disease resistance traits are candidates for the implementation of MAS and, especially, GAS programs, which would allow the evaluation of individuals without exposing them to the pathogen or relying on relatives' information alone.

There have been a certain number of studies on disease resistance QTL in the main aquaculture species, especially focused in rainbow trout and Atlantic salmon within fish. In rainbow trout, several QTL were detected for resistance to IPN and IHN (Infectious Hematopoietic Necrosis) viruses [20-23] and to different parasites, including Ceratomyxa shasta and Myxobolus cerebralis [24,25]. The identified QTL in response to IHN virus were detected in more than one family supporting their consistency [22], and in the case of resistance to Myxobolus cerebralis, a very strong association was detected which explained between 50 and $86 \%$ of the phenotypic variance across families [25]. In Atlantic salmon, QTL for disease resistance have been reported for the ISA (Infectious Salmon Anaemia) virus [26], for the bacterium Aeromonas salmonicida responsible of furunculosis [27] and for the ectoparasite Gyrodactylus salaries [28]. Of particular relevance in this species was a recent study on ten full-sib families for mapping QTL for resistance against the IPN virus in postsmolts of Scottish origin, based on data from a field trial [29]. In this study, a major QTL explained up to $21 \%$ of the phenotypic variation in the data set and was found to segregate in 7 out of 20 parents investigated. Additionally, this QTL mapped to the same location of a recently detected QTL for IPN-resistance that explained 29\% of the phenotypic variance using ten large full-sib families of challenge-tested Norwegian Atlantic salmon. This particular QTL was found to be segregating in 10 out of 20 parents, and a subsequent fine-mapping with additional markers narrowed the QTL peak to a $4 \mathrm{cM}$ region on 
linkage group 21 [3]. This QTL, detected in two different populations, is now being implemented in within-family selection in both Scotland [30] and Norway [3]. QTL for disease resistance have also been reported in a few cases in non-salmonid teleosts, including those for stress/immune response in tilapia [31], for resistance to pasteurellosis in gilthead sea bream [32] and for resistance to lymphocystis viral disease in Japanese flounder [33]. Other QTL for disease resistance traits in aquaculture species were identified in Crassostrea virginica, Ostrea edulis and Paralichthys olivaceus [see 7 for a review].

To date, only two studies identified QTL in turbot. One detected a QTL for body length highly associated with the marker YSKr51, explaining $12.4 \%$ of the phenotypic variance [34], and the other one identified a significant sex-determining QTL highly associated with the SmaUSCE30 marker, which allowed for correct sex determination in up to $98.4 \%$ of the studied individuals [35]. The construction of a genetic map with appropriate marker density is necessary to detect QTL controlling quantitative traits of economic interest in aquaculture [20]. However, genetic linkage maps of most aquaculture species have only recently been available. Bouza et al. [17] reported an updated consensus including a total of 273 microsatellites clustered in 26 linkage groups, comprising $1343.2 \mathrm{cM}$ length, with an average distance between markers of $6.5 \pm$ $0.5 \mathrm{cM}$.

In the present work, a genome scan for QTL affecting resistance and survival to $A$. salmonicida in four turbot families was carried out using the reported microsatellite panel. The objectives were: (1) to locate QTL on the available linkage map, (2) to compare QTL obtained through the use of two different methodologies: linear regression and maximum likelihood, and (3) to determine the association between markers and traits.

\section{Methods \\ Families}

Four full-sib turbot families were used to identify QTL for resistance and survival to $A$. salmonicida and to evaluate the association of those traits with the genotyped markers. Three of these families were obtained from the Stolt Sea Farm S.A. breeding program (FamAS-1, FamAS-2 and FamAS-3) and one family was obtained from Insuiña S.A. $($ FamAP). Both companies have their facilities located in NW Spain.

Since no selected strains for high and low disease resistance exist in turbot, families were selected trying to emphasize genetic divergence between parents to detect as much as possible allelic variants associated with resistance. Thus, families founded with unrelated grandparents and, when possible, from different Atlantic origins, were chosen. Also, we selected families where a threegeneration pedigree was available. This enabled us to know the linkage-phase between markers for a more consistent statistical analysis. This process finally led to four independent full-sib pair analyses.

\section{Trait measurement}

All offspring of each family (approximately 150 individuals per family) were intracelomically injected at the age of four months (mean weight around $20 \mathrm{~g}$ ) with a highly virulent $A$. salmonicida strain. Although $A$. salmonicida infection was previously reported to last around 21 days [11], the experiment was prolonged to 39 days to increase phenotypic variance for survival. After injection, two disease resistance related traits were evaluated: resistance $(R e)$ and survival $(\mathrm{Su})$. Around one hundred individuals for each family were selected to evaluate both traits (the 50 most resistant and the 50 most sensitive individuals). The dichotomous trait $R e$ was defined as the survival $v s$ non survival status of individuals at the end of the experiment (i. e. day 39 after the injection). The trait $S u$ was defined as the number of days one individual survived (i.e. elapsed days until the individual died or the experiment finished). Consequently, this is a censored trait since all individuals still alive at the end of the study were scored with the same value for survival.

\section{Genetic map}

The panel of markers used for QTL identification was reported by Martínez et al. [35] and it is based on the consensus map by Bouza et al. [15], the new EST-linked microsatellites by Bouza et al. [17] and the centromere mapping [16].

Table 1 shows the number of analyzed microsatellites, the number of linkage groups, the map length, the average distance between microsatellites and the average number of microsatellites per linkage group. The average distance between markers in the map ranged between 15.53 and $16.06 \mathrm{cM}$, being below the minimum distance proposed for QTL detection $(<20 \mathrm{cM})$ [36].

\section{QTL analyses}

Two programs were used to detect QTLs: GridQTL [37] and QTLMap [38]. Within both methodologies, two approaches were followed. First, a single QTL was

Table 1 Screening figures in the four families analyzed for QTL identification

\begin{tabular}{cccccc}
\hline Family & NM & LG & MLe & D & NMG \\
\hline FamAS-1 & 104 & 22 & 1147.80 & 15.62 & 4.73 \\
FamAS-2 & 98 & 22 & 1105.10 & 15.53 & 4.46 \\
FamAS-3 & 99 & 22 & 1132.30 & 15.90 & 4.50 \\
FamAP & 101 & 23 & 1149.40 & 16.06 & 4.39 \\
\hline
\end{tabular}

NM: Number of markers; LG: linkage groups; MLe: map length in $\mathrm{CM}$; $\mathrm{D}$ : average distance between markers in CM; NMG: mean number of microsatellites per linkage group. 
assumed at each LG. Afterwards, a two-QTL model was also tested within each LG.

\section{GridQTL}

This software http://www.gridqtl.org.uk/ implements a linear regression (LR) methodology, considering the linkage phase between markers according to pedigree information. The default regression method [39] was applied, and the genome and chromosome-wide significance thresholds were estimated by implementing bootstrapping at $p=0.05$ and 0.01 [40], with a permutation test of 10,000 iterations [41].

\section{QTLmap}

This software https://qgp.jouy.inra.fr/index.php?option=com_content\&task=view\&id=17\&Itemid=28 detects QTL through interval mapping using a maximum likelihood (ML) test. To determine the significance level 10, 000 simulations were performed for each trait and LG, with a heritability set to 0.10 [42].

For both methodologies, an outbred full-sib model was used and a QTL was considered suggestive when significance was between $5 \%$ and $1 \%$ at chromosome-wide level, and significant when significance was below $1 \%$ at chromosome-wide level or when significance was below $5 \%$ at genome-wide level [43]. These thresholds also allow establishing a confidence interval to allocate the detected QTL.

Sex was not included into the model because it was not available. Although there is some debate about the influence of growth-related traits on the resistance to diseases (see for example [44] for positive results, and [45] and [46] for absence of correlations between both types of traits), weight and length were included as covariates within the model to reduce the stochasticity.

\section{Association analyses}

A one way analysis of variance (ANOVA) was performed on the phenotypic values (resistance and survival) of the progeny for each family using individual genotypes from markers within the LGs where a significant or suggestive QTL was found. The objective was to detect associations between markers and traits by estimating the betweengenotype component of the observed phenotypic variance (i.e. differences attributable to the different marker genotypes). To avoid false positives due to multiple testing, a simple Bonferroni correction was performed for all tests involving those markers within the same LG. Each ANOVA also provided a corrected $R^{2}$ value useful to estimate the reduction of the overall phenotypic variance of the trait due to the model fitting, thus providing the proportion of the trait variance predictable from the given marker genotypes.

\section{Results and Discussion Trait values}

Table 2 shows the number of observations and the mean for the traits recorded (resistance and survival) in the four families of the experiment. The standard deviation ranged between 13.12 - 15.31 days for survival and $0.44-0.50$ for resistance. Notice that a greater power for detection is expected in challenges where there is approximately a $50 \%$ of survival $\left(\mathrm{LD}_{50}\right)$, as it occurred in $A S$ families. Although a lower survival (26\%) was observed for family $A P$, this did not preclude the detection of QTL in that family (see Table 3). Mean weight and length ranged between $31.62-46.45 \mathrm{~g}$ and 10.70 $12.83 \mathrm{~cm}$, respectively.

\section{QTL analyses}

Table 3 shows the location of the detected QTL (LG, estimated position and interval) with both methodologies (LR and ML). There were no QTL at genome-wide level with the LR approach, but two suggestive (LG12 and LG13) and three significant (LG4, LG6 and LG9) QTL were detected for resistance, and four suggestive (LG4, LG11, LG12 and LG13) and two significant (LG6 and LG9) QTL were detected for survival at chromosome-wide level. Using the ML methodology, one QTL for resistance (LG6) and three for survival (LG5, LG6 and LG9) were identified at genome-wide level with significance below 1\%. Additionally, three suggestive (LG4, LG12 and LG16) and two significant (LG5 and LG9) QTL for resistance, and five suggestive (LG1, LG4, LG12, LG16 and LG18) QTL for survival were detected at chromosome level.

Table 2 Statistics of the measured traits in the four families analyzed ( \pm standard deviation)

\begin{tabular}{|c|c|c|c|c|c|}
\hline Family & Weight (g) & Length $(\mathrm{cm})$ & Trait & $N$ & Mean \\
\hline FamAS-1 & $46.45 \pm 8.49$ & $12.83 \pm 0.78$ & $\begin{array}{l}\text { Re } \\
\text { Su }\end{array}$ & $\begin{array}{l}100 \\
100\end{array}$ & $\begin{array}{c}0.5 \\
24.44\end{array}$ \\
\hline FamAS-2 & $26.69 \pm 6.00$ & $10.70 \pm 0.77$ & $\begin{array}{l}\text { Re } \\
\text { Su }\end{array}$ & $\begin{array}{l}100 \\
100\end{array}$ & $\begin{array}{c}0.5 \\
24.17\end{array}$ \\
\hline FamAS-3 & $31.62 \pm 7.18$ & $11.33 \pm 0.86$ & $\begin{array}{l}\text { Re } \\
\text { Su }\end{array}$ & $\begin{array}{l}100 \\
100\end{array}$ & $\begin{array}{c}0.5 \\
23.58\end{array}$ \\
\hline FamAP & $32.13 \pm 5.20$ & $11.43 \pm 0.59$ & $\begin{array}{l}\text { Re } \\
\text { Su }\end{array}$ & $\begin{array}{l}113 \\
113\end{array}$ & $\begin{array}{c}0.26 \\
17.04\end{array}$ \\
\hline
\end{tabular}


Table 3 Location of the QTL detected for resistance and survival to A. salmonicida with two different statistical methodologies

\begin{tabular}{|c|c|c|c|c|c|c|c|c|c|c|c|c|c|}
\hline \multirow[b]{3}{*}{ Family } & \multirow[b]{3}{*}{ LG } & \multicolumn{6}{|c|}{ Resistance } & \multicolumn{6}{|c|}{ Survival } \\
\hline & & \multicolumn{3}{|c|}{ LR } & \multicolumn{3}{|c|}{$\mathrm{ML}$} & \multicolumn{3}{|c|}{ LR } & \multicolumn{3}{|c|}{ ML } \\
\hline & & EP & Interval & Sig. & EP & Interval & Sig. & EP & Interval & Sig. & EP & Interval & Sig. \\
\hline \multirow[t]{3}{*}{ FamAS-2 } & 4 & 0 & $0-11$ & * & 10 & $0-18$ & $\mathrm{~s}$ & 0 & $0-15$ & $\mathrm{~s}$ & 10 & $0-19$ & $\mathrm{~s}$ \\
\hline & 11 & & & & & & & 43 & $37-44$ & s & & & \\
\hline & 16 & & & & 49 & $46-49$ & $\mathrm{~s}$ & & & & 49 & $41-49$ & s \\
\hline \multirow[t]{4}{*}{ FamAS-3 } & 1 & & & & & & & & & & 1 & $0-8$ & s \\
\hline & 6 & 0 & $0-42$ & * & 26 & $0-66$ & $* *$ & 0 & $0-43$ & * & 26 & $0-66$ & $* *$ \\
\hline & 9 & & & & 66 & $64-66$ & s & & & & & & \\
\hline & 12 & 52 & $49-52$ & s & 52 & $50-53$ & s & 52 & $51-52$ & s & 52 & $50-53$ & $s$ \\
\hline \multirow[t]{5}{*}{ FamAP } & 5 & & & & 21 & $5-36$ & * & & & & 19 & $10-29$ & $* *$ \\
\hline & 9 & 31 & $27-35$ & * & 38 & $29-45$ & $*$ & 31 & $24-37$ & * & 36 & $31-40$ & $* *$ \\
\hline & 13 & 0 & $0-4$ & s & & & & 0 & $0-4$ & s & & & \\
\hline & 16 & & & & 35 & $21-49$ & $\mathrm{~s}$ & & & & 36 & $23-55$ & s \\
\hline & 18 & & & & & & & & & & 16 & $12-26$ & s \\
\hline
\end{tabular}

LR: linear regression; ML: maximum likelihood; LG: linkage group; EP: estimated position (in CM); Interval: confidence range of the detected QTL (in CM); Sig.: significance level; QTL was considered suggestive (s) when significance was between $5 \%$ and $1 \%$ at chromosome-wide level, and significant when significance was below $1 \%$ at chromosome-wide level $\left(^{*}\right)$ or when significance was below $5 \%$ at genome-wide level $\left({ }^{* *}\right)$.

In our study, four full-sib families from segregating populations were evaluated separately using two different methodologies. Kao [47] investigated the performances of LR and ML methods for QTL detection, suggesting the application of LR as an initial procedure to obtain preliminary results and then use the ML method as a final procedure in order to obtain the most conclusive results. Our data support in part Kao's suggestion, since the highest significance levels were yielded by ML for the same QTL detected with both methodologies. The concordance in QTL location between both methods or between different families (LG16 in FamAS-2 and FamAP; see Table 3) increases the confidence of the results obtained.

QTL were less significant when length and weight were excluded from the model (data not shown) indicating that body size may contribute to or may be correlated with another trait affecting disease resistance. The regression coefficients for the covariates themselves were not significant except for body weight in one of the families $($ FamAP). Overturf et al. [44] indicated a positive correlation between body size and disease resistance related traits, but other authors detected no significant correlation between both types of traits $[45,46]$. Although the inclusion of body size improved QTL detection in our study, the exact relationship with resistance to A. salmonicida is not known.

Classical QTL mapping methods assume that traits follow a normal distribution [48]. However, the categorical (dead or alive) and survival (length of life) data used in this study are not-normally distributed. For such traits, classical QTL detection methods could have a lower power and a bias when estimating the effects and position of QTL. Nevertheless, it has been proposed that classical interval mapping methods using a Gaussian model on censored data, analyzed as if they were uncensored, have not a reduced accuracy on QTL location and estimation of QTL effects [49].

As can be seen in Table 3, several QTL were detected for resistance and survival at close positions within the same LG. One reason for this agreement could be the high relationship expected between both traits, since the resistance concept also includes survival (resistant individuals survive for a long period, in fact the whole experiment). Other reason could be that the same genes were involved in the mechanisms underlying both disease resistance traits.

The power to detect QTL depends on the heritability of the trait, the recombination distance between QTL and markers, the proportion of phenotypic variance explained by the QTL, the QTL allele frequency and the sample size [50]. In addition, the power of QTL analysis is limited, since only QTL segregating in one or both parents can be detected. In fact, there were no QTL detected within FamAS-1. Considering that families come from unrelated and genetically divergent grandparents from natural populations of the Atlantic area, identified QTL in our study could be representative of the genetic architecture of disease resistance related traits in turbot. Anyway, the detected QTL should be verified in other turbot families before their use in breeding programs. 
The probability of success and the accuracy of results of QTL studies depend on the precision and density of the available genetic map. Following this idea, the map used in this study is being further refined and, thus, the QTL detection could also be improved. Currently, Martínez et al. (unpublished data) are developing a consensus map comprising 463 markers (microsatellites and EST) with a moderately dense coverage.

\section{Association analyses}

All markers within the same linkage group where a suggestive or significant QTL was detected were analyzed. Table 4 shows the results only for markers significantly associated with any of the traits. At least one significantly associated marker was found in all linkage groups where a QTL was detected, except for LGs 1, 12, 13 and 18. However, within these LGs only suggestive QTL were detected (see Table 3). Remarkably, not always the most significantly associated markers were the closest to the estimated position of the QTL (data not shown). The reasons could be: (1) low information content of the closest marker due to the parents genotype; (2) a large extension of the area in linkage disequilibrium with the detected
QTL, which could result in positive associations between the trait and the genotypes at several markers; (3) the existence of a secondary segregating QTL, although this situation was not detected when LGs were analyzed for the possibility of carrying two QTL; and finally (4) marker positions in the map are not definitive, which could modify the order and the distance between markers. For example, it should be noticed that the present genetic map of turbot has more linkage groups (26) than chromosomes observed in this species $(2 n=44$ chromosomes) [51].

Markers showing significant association with studied traits explained from 7 to $17 \%$ of the phenotypic variance. The marker SmaUSC-E30, significantly associated with resistance and survival traits at LG5, was previously associated to the major QTL for sex determination in turbot [35]. This may suggest an influence of sex in the measured traits that could be related either to the reported growth rate differences between sexes in turbot [52] or to sex-susceptibility/immune differences [53]. A relationship between growth and immune function was previously reported in fish $[54,55]$. In the case of LG9, up to three markers showed significant association with

Table 4 Proportion of the phenotypic variance explained by the markers significantly associated with the evaluated traits

\begin{tabular}{|c|c|c|c|c|c|c|}
\hline Trait $^{1}$ & Family & LG & $\begin{array}{c}\text { Method }^{2} \text { and } \\
\text { QTL position (cM) }\end{array}$ & Marker $^{3}$ & $\begin{array}{c}\text { Marker } \\
\text { position }(\mathrm{cM})^{4}\end{array}$ & $R^{2}(\%)$ \\
\hline \multirow[t]{7}{*}{ Re } & FamAS-2 & 4 & LR: 0/ML: 10 & Sma-USC47 & 0.00 & 7.4 \\
\hline & FamAS-3 & 6 & LR: 0/ML: 26 & Sma-USC147 & 4.52 & 16.2 \\
\hline & FamAP & 5 & ML: 21 & SmaUSC-E30 & 0.00 & 8.9 \\
\hline & & 9 & LR: 31/ML: 38 & SmaUSC-E23 & 30.75 & 10.5 \\
\hline & & & & SmaUSC-E41 & 45.68 & 12.4 \\
\hline & & & & Sma-USC21 & 53.91 & 11.6 \\
\hline & & 16 & ML: 35 & Sma-USC256 & 32.75 & 13.6 \\
\hline \multirow[t]{8}{*}{ Su } & FamAS-2 & 4 & LR: 0/ML: 10 & Sma-USC47 & 0.00 & 8.1 \\
\hline & & 11 & LR: 43 & Sma-USC158 & 23.39 & 10.1 \\
\hline & FamAS-3 & 6 & LR: 0/ML: 26 & Sma-USC147 & 4.52 & 16.8 \\
\hline & FamAP & 5 & ML: 19 & SmaUSC-E30 & 0.00 & 8.9 \\
\hline & & 9 & LR: 31/ML: 36 & SmaUSC-E23 & 30.75 & 12.3 \\
\hline & & & & SmaUSC-E41 & 45.68 & 12.8 \\
\hline & & & & Sma-USC21 & 53.91 & 12.0 \\
\hline & & 16 & ML: 36 & Sma-USC256 & 32.75 & 12.4 \\
\hline
\end{tabular}

${ }^{1} \operatorname{Re}$ : resistance; Su: survival.

LG: linkage group.

${ }^{2}$ LR: linear regression method; ML: maximum likelihood method;

${ }^{3}$ BLAST annotation [17] was only recorded for Sma-USC23 (3-Hydroxibutirate dehydrogenase type 2) and Sma-USC41 (Helicase with zinc finger domain).

${ }^{4}$ Marker position in centimorgan (CM) within the genetic map by Bouza et al. [17].

$R^{2}(\%)$ : proportion of the explained phenotypic variance. 
both traits (Table 4: SmaUSC-E23, SmaUSC-E41 and Sma-USC21), the two first ones being functionally annotated as immune-related genes [14].

A high explained phenotypic variance was also observed for an IPN-resistance QTL in salmonids 21\% [29] and 29\% [3]. A QTL for ISA-resistance, also in Atlantic salmon, explained 6 - 9\% of the phenotypic variance [26]. In rainbow trout two QTL for IPN-resistance were identified explaining 27 and 34\% of the phenotypic variance, respectively [20].

Several associations have been detected in teleosts between disease resistance and candidate genes, mostly involving polymorphism of the Major Histocompatibility Complex (MHC), an essential gene family for adaptive immunity [7]. In rainbow and cutthroat trout, an association was detected with the resistance to IHN virus [56]; in rainbow trout, a suggestive association with the resistance to Bacterial Cold Water Disease (BCWD) [57]; and in Atlantic salmon, associations were detected for resistance to A. salmonicida [27,58,59], IHN [60], and ISA [27]. Beyond salmonids, associations between MHC markers and disease resistance have also been reported in other important farmed teleosts like Japanese flounder (resistance to Vibrio anguillarum) [61]; common carp (resistance to Cyprinid Herpesvirus-3) [62], and in the turbot (resistance to Edwardsiella tarda) [63]. Several of these associations involved the MHC class IIB gene, an observation which strongly recommends the mapping of this gene in turbot to cross this information against the QTL locations from this study and to evaluate its possible role in general resistance to bacterial pathogens. Nevertheless, direct selection on $\mathrm{MHC}$ variants could be not advisable since balancing selection [57] or overdominance [64] have been suggested to be acting on this polymorphism. The risk of pathogen-specific allelic selection could determine undesired loss of MHC variation, which may increase susceptibility to other pathogens. Furthermore, it has been highlighted that other genes may also play an important role to explain genetic variance for disease resistance [7]. Recently, significant associations with other relevant immune-genes have been reported in common carp (Interleukin 10 (IL-10) with resistance to cyprinid herpesvirus-3 [65]) and in grass carp (Toll-like Receptor-3 (TLR3) with resistance to reovirus [66]).

A revision and a refinement of the mapping regions where QTL were located should be performed to further narrow the intervals and facilitate the advance on candidate gene strategies. Also, mapping of differentially expressed (DE) genes identified in response to A. salmonicida infections [14] should be evaluated or acquired to cross this information with QTL position. None of the immune-related genes significantly associated with resistance and survival traits in this study (SmaUSC-E23, SmaUSC-E41) were found to be regulated in response to
A. salmonicida infection [14]. Nevertheless, two DE genes detected in response to this pathogen [14] were located in the vicinity of two QTL at LG9 and LG11, respectively. SmaUSC-E41, linked to the immune-related DE ecdysone receptor A (BLAST annotation; E-value: $3 \mathrm{E}^{-8}$ ), was located at LG9 close to the marker SmaUSC-E5 [4 cM; see [17]]. This gene pertains to a nuclear receptor superfamily present in all Metazoa, containing ligand dependent transcription factors related to immune system and regulation of inflammatory processes [67]. On the other hand, SmaUSC147 was 7 cM apart from the significantly associated SmaUSC-E24 marker at LG11. This marker is linked to a DE gene (annotated as PRA1 family protein 3 using BLAST; E-value: $3 \mathrm{E}^{-9}$ ), which modulates antiapoptotic activity and immune response [68]. Since these DE markers were not included in the panel of markers for QTL screening in this work, further association analysis across the same QTL families should be carried out. Finally, markers linked to relevant DE genes in the turbot and previously associated with disease resistance in other fish (e.g., TLR3, MHC class IA and MHC IIA) [14,66,7], should be mapped. This would enable to test their association within families to provide new candidates for a functional explanation of resistance to $A$. salmonicida in the turbot.

If the responsible gene and the causal mutation were detected, then, GAS could be performed. Increasing map density should facilitate the detection of more closely linked markers useful to implement MAS. For both strategies, another promising approach is the use of comparative genomics [69]. A study of comparative mapping by Bouza et al. [15] identified syntenic relationships between sequences of turbot and the model fish Tetraodon nigroviridis (Tni): between turbot LG16 and Tni chromosome 19; between turbot LG5 and Tni1; and between turbot LG6 and Tni13. Since in the present study QTL at LG5, LG6 and LG16 were detected, the analysis of genes located at these syntenic blocks in $T$. nigroviridis through comparative genomics tools with the turbot DE genes in response to $A$. salmonicida [14] could provide relevant information about candidates underlying the detected QTL.

Finfish aquaculture is still relatively in its first stages in the large-scale animal production sector. However, it can take advantage on the vast amounts of genomic data currently being generated for livestock, as well as for model fish organisms. Many livestock genomics programs have focused on identifying genes influencing similar economic traits as those important in aquaculture, such as growth rate, disease resistance and meat quality traits. Through comparative genomic approaches, sequence information from other vertebrates can be used to quickly isolate homologous genes in finfish. It could be also interesting to extend this study to other pathogens 
for detection of disease resistance related QTL affecting turbot aquaculture systems in order to investigate more general disease resistance related traits.

\section{Conclusions}

Regions controlling resistance-related traits to Aeromonas salmonicida in turbot were detected. Concordance on the detection of QTL between statistical methods gives more consistency to our results. A finer mapping will be necessary on those linkage groups with effect on disease resistance by increasing the density of markers on the position where the QTL were detected. In addition, functional and comparative genomics strategies could be used to confirm the detected QTL and to look for candidate genes. Alternatively, the associated markers could be useful in programs for marker-assisted selection in turbot.

\begin{abstract}
Acknowledgements
We thank two anonymous referees for helpful comments on the manuscript. This study was supported by the Spanish government projects (Consolider Ingenio Aquagenomics: CSD200700002; MCl: CGL2009-13278-C02 and AGL2009-13273), and Xunta de Galicia and Fondos Feder (Grupos de Referencia Competitiva, 2010/80). B. G. P. was supported by an Isidro Parga Pondal research fellowship from Xunta de Galicia (Spain).
\end{abstract}

\section{Author details}

${ }^{1}$ Departamento de Bioquímica, Genética e Inmunología, Facultad de Biología, Universidad de Vigo, 36310 Vigo, Spain. ${ }^{2}$ Departamento de Producción Animal, ETS Ingenieros Agrónomos, Universidad Politécnica de Madrid, Ciudad Universitaria, 28040 Madrid, Spain. ${ }^{3}$ Departamento de Genética, Facultad de Veterinaria, Universidad de Santiago de Compostela, 27002, Lugo, Spain. ${ }^{4}$ Cluster de la Acuicultura de Galicia (CETGA), A Coruña, 15965, Spain. ${ }^{5}$ Departamento de Mejora Genética Animal, Instituto Nacional de Investigación y Tecnología Agraria y Alimentaria, Ctra. A Coruña Km. 7.5, 28040 Madrid, Spain.

\section{Authors' contributions}

STRR was responsible of the final version of QTL and marker analysis and the writing of the article. MAT and JF were responsible of the supervision of the QTL and marker analysis and also of the supervision of the article. CB, $\mathrm{MH}$ and BGP performed genotyping at all families and contributed to discussion on association analysis. SC was responsible of challenges of fish and measuring of phenotypic traits. PM was responsible of the work and supervised all tasks. JF was responsible for a first version of the QTL analysis. All authors read and approved the final manuscript.

Received: 13 May 2011 Accepted: 2 November 2011

Published: 2 November 2011

\section{References}

1. Wedemeyer G: Physiology of fish in intensive culture systems London, Chapman \& Hall; 1996

2. Duarte CM, Marbá N, Holmer M: Rapid domestication of marine species. Science 2007, 316:383-383.

3. Moen T, Baranski M, Sonesson AK, Kjøglum S: Confirmation and finemapping of a major QTL for resistance to infectious pancreatic necrosis in Atlantic salmon (Salmo salar): population-level associations between markers and trait. BMC Genomics 2009, 10:368.

4. Storset A, Strand C, Wetten M, Kjøglum S, Ramstad A: Response to selection for resistance against infectious pancreatic necrosis in Atlantic salmon (Salmo salar L.). Aquaculture 2007, 272:62-68.

5. Okamoto N, Tayama T, Kawanobe M, Fujiki N, Yasuda Y, Sano T: Resistance of a rainbow trout strain to infectious pancreatic necrosis. Aquaculture 1993, 117:71-76

6. Schäperclaus W: Traité de pisciculture en étang Paris, Vigot Frères; 1962.
7. Ødegård J, Baranski M, Gjerde B, Gjedrem T: Methodology for genetic evaluation of disease resistance in aquaculture species: challenges and future prospects. Aquaculture Research 2011, 42:103-114.

8. Perry GML, Tarte $P$, Croisetière $S$, Belhumeur $P$, Bernatchez L: Genetic variance and covariance for $0+$ brook charr (Salvelinus fontinalis) weight and survival time of furunculosis (Aeromonas salmonicida) exposure. Aquaculture 2004, 235:263-271.

9. APROMAR: Informe anual sobre el desarrollo de la acuicultura marina en España y el mundo España; 2010.

10. Ellis AE: Immunization with bacterial antigens: furunculosis. In Fish Vaccinology. Edited by: Gudding R, Lillehaug A, Midtlyng PJ, Brown PR. Karger, Basel; 1997:107-116.

11. Austin B, Austin DA: Bacterial fish pathogens. Diseases of farmed and wild fish United Kingdom, Springer-Praxis Publishing Ltd; 1999.

12. Pardo BG, Fernández C, Millán A, Bouza C, Vázquez-López A, Vera M, Álvarez-Dios JA, Calaza M, Gómez-Tato A, Vázquez M, Cabaleiro S, Magariños B, Lemos ML, Leiro JM, Martínez P: Expressed sequence tags (ESTs) from immune tissues of turbot (Scophthalmus maximus) challenged with pathogens. BMC Vet Res 2008, 4:37.

13. Vera M, Álvarez-Dios JA, Millán A, Pardo BG, Bouza C, Hermida M, Fernández C, de la Herrán R, Molina-Luzón J, Martínez P: Validation of single nucleotide polymorphism (SNP) markers from an immune expressed sequence tag (EST) turbot, Scophthalmus maximus, database. Aquaculture 2011, 313:31-41.

14. Millán A, Gómez-Tato A, Fernández C, Pardo BG, Álvarez-Dios JA, Calaza M, Bouza C, Vázquez M, Cabaleiro S, Martínez P: Design and performance of a turbot (Scophthalmus maximus) oligo-microarray based on ESTs from immune tissues. Mar Biotechnol 2010, 12:452-465.

15. Bouza C, Hermida M, Pardo BG, Fernández C, Castro J, Fortes GG, Sánchez L, Presa P, Pérez M, Sanjuán A, Comesaña S, Álvarez-Dios JA, Calaza M, Cal R, Piferrer F, Martínez P: A microsatellite genetic map in the turbot (Scophthalmus maximus). Genetics 2007, 177:2457-2467.

16. Martínez P, Hermida M, Pardo BG, Fernández C, Castro J: Centromerelinkage in the turbot (Scophthalmus maximus) through half-tetrad analysis in diploid meiogynogenetics. Aquaculture 2008, 280:81-88.

17. Bouza C, Hermida M, Millán A, Vilas R, Vera M: Characterization of ESTderived microsatellites for gene mapping and evolutionary genomics in turbot. Anim Genet 2008, 39:666-670.

18. Mackay TFC: The genetic architecture of quantitative traits. Ann Rev Genet 2001, 35:303-339.

19. Lynch M, Walsh B: Genetics and analysis of quantitative traits Sunderland, Sinauer Associates; 1998.

20. Ozaki A, Sakamoto T, Khoo S, Nakamura K, Coimbra MR, Akutsu T, Okamoto N: Quantitative trait loci (QTLs) associated with resistance/ susceptibility to infectious pancreatic necrosis virus (IPNV) in rainbow trout (Oncorhynchus mykiss). Mol Genet Genomics 2001, 265:23-31.

21. Palti $Y$, Parsons JE, Thorgaard GH: Identification of candidate DNA markers associated with $\mathrm{IHN}$ virus resistance in backcrosses of rainbow (Oncorhynchus mykiss) and cutthroat trout (O clarki). Aquaculture 1999, 173:81-94

22. Rodríguez MF, Lapatra S, Williams S, Famula T, May B: Genetic markers associated with resistance to infectious hematopoietic necrosis in rainbow and steelhead trout. Aquaculture 2004, 241:93-115.

23. Barroso RM, Wheeler PA, Lapatra SE, Drew RE, Thorgaard GH: QTL for IHNV resistance and growth identified in a rainbow (Oncorhynchus mykiss) $\times$ Yellowstone cutthroat (Oncorhynchus clarki bouvieri) trout cross. Aquaculture 2008, 277:156-163.

24. Nichols KM, Bartholomew J, Thorgaard GH: Mapping multiple genetic loci associated with Ceratomyxa shasta resistance in Oncorhynchus mykiss. Dis Aquat Organ 2003, 56:145-54.

25. Baerwald MR, Petersen JL, Hedrick RP, Schisler GJ, May B: A major effect quantitative trait locus for whirling disease resistance identified in rainbow trout (Oncorhynchus mykiss). Heredity 2010, 106:920-926.

26. Moen T, Sonesson AK, Hayes B, Lien S, Munck H, Meuwissen THE: Mapping of a quantitative trait locus for resistance against infectious salmon anaemia in Atlantic salmon (Salmo Salar): comparing survival analysis with analysis on affected/resistant data. BMC Genetics 2007, 8:53.

27. Grimholt U, Larsen S, Nordmo R, Midtlyng P, Kjoeglum S, Storset A, Saebo S, Stet RJM: MHC polymorphism and disease resistance in Atlantic salmon (Salmo salar); facing pathogens with single expressed major 
histocompatibility class I and class II loci. Immunogenetics 2003, 55:210-219.

28. Gilbey J, Verspoor E, Mo TA, Sterud E, Olstad K, Hytterød S, Noble LR, Jones CS: Identification of genetic markers associated with Gyrodactylus salaris resistance in Atlantic salmon (Salmo salar L). Diseases of Aquatic Organisms 2006, 71:119-129.

29. Houston RD, Haley CS, Hamilton A, Guy DR, Tinch AE, Taggart JB, Mcandrew BJ, Bishop SC: Major quantitative traits loci affect resistance to infectious pancreatic necrosis in Atlantic salmon (Salmo salar). Genetics 2008, 178:1109-1115

30. Houston RD, Haley CS, Hamilton A, Guy DR, Mota-Velasco JC, Gheyas AA, Tinch AE, Taggart JB, Bron JE, McAndrew BJ, Verner-Jeffreys DW, Paley RK, Rimmer GSE, Tew IJ, Bishop SC: The susceptibility of Atlantic salmon fry to freshwater infectious pancreatic necrosis is largely explained by a major QTL. Heredity 2009, 105:318-327.

31. Cnaani A, Zilberman N, Tinman S, Hulata G, Ron M: Genome-scan analysis for quantitative trait loci in an F2 tilapia hybrid. Mol Genet Genomics 2004, 272:162-172

32. Massault C, Franch R, Haley C, de Koning DJ, Bovenhyis H, Pellizzan C, Patarnello T, Bargelloni L: Quantitative trait loci for resistance to fish pasteurellosis in gilthead sea bream (Sparus aurata). Animal Genetics 2011, 42:191-203.

33. Fuji K, Kobayashi K, Hasegawa O, Coimbra MR, Sakamoto T, Okamoto N: Identification of a single major genetic locus controlling the resistance to lymphocystis disease in Japanese flounder (Paralichthys olivaceus). Aquaculture 2006, 254:203-210.

34. Ruan XH, Wang WJ, Kong J, Yu F, Huang XQ: Genetic linkage mapping of turbot (Scophthalmus maximus L.) using microsatellite markers and its application in QTL analysis. Aquaculture 2010, 308:89-100.

35. Martínez P, Bouza C, Hermida M, Fernández J, Toro MA, Vera M, Pardo BG, Millán A, Fernández C, Vilas R, Viñas A, Sánchez L, Felip A, Piferrer F, Ferreiro I, Cabaleiro S: Identification of the major sex-determining region of turbot (Scophthalmus maximus). Genetics 2009, 183:1443-52.

36. Dekkers JCM, Hospital F: The use of molecular genetics in the improvement of agricultural populations. Nat Rev Genet 2002, 3:22-32.

37. Seaton G, Hernández J, Grunchec JA, White I, Allen J, De Koning DJ, Wei W, Berry D, Haley C, Knott S: GridQTL: A grid portal for QTL mapping of compute intensive datasets. Proceedings of the 8th World Congress on Genetics Applied to Livestock Production Belo Horizonte, Brazil; 2006.

38. Gilbert H, Le Roy P, Moreno C, Robelin D, Elsen JM: QTLMAP, a software for QTL detection in outbred population. Annals of Human Genetics 2008, 72(5):694.

39. Haseman JK, Elston RC: The investigation of linkage between a quantitative trait and a marker locus. Behav Genet 1972, 2:3-19.

40. Visscher P, Thompson R, Haley C: Confidence intervals in QTL mapping by bootstrapping. Genetics 1996, 143:1013-1020.

41. Churchill GA, Doerge RW: Empirical threshold values for quantitative trait mapping. Genetics 1994, 138:963-971.

42. Antonello J, Massault C, Francha R, Haley CS, Pellizzari C, Bovo G, Atarnello Th, de Koning DJ, Bargelloni L: Estimates of heritability and genetic correlation for body length and resistance to fish pasteurellosis in the gilthead sea bream (Sparus aurata L.). Aquaculture 2009, 298:29-35.

43. Lander $E$, Kruglyak $L$ : Genetic dissection of complex traits: guidelines for interpreting and reporting linkage results. Nature Genet 1995, 11:241-247.

44. Overturf K, Lapatra S, Towner R, Campbell N, Narum S: Relationships between growth and disease resistance in rainbow trout, Oncorhynchus mykiss (Walbaum). J Fish Dis 2010, 33:321-329.

45. Henryon M, Jokumsenb A, Berga P, Lundb I, Pedersenb PB, Olesenc NJ, Slierendrechtc WJ: Genetic variation for growth rate, feed conversion efficiency, and disease resistance exists within a farmed population of rainbow trout. Aquaculture 2002, 209:59-76.

46. Silverstein JT, Vallejo RL, Palti Y, Leeds TD, Rexroad CD III, Welch TJ, Wiens GD, Ducrocq V: Rainbow trout resistance to bacterial cold-water disease is moderately heritable and is not adversely correlated with growth. J Anim Sci 2009, 87:860-867.

47. Kao CH: On the differences between maximum likelihood and regression interval mapping in the analysis of quantitative trait loci. Genetics 2000, 156:855-865.

48. Knott SA, Elsen JM, Haley CS: Methods for multiple marker mapping of quantitative trait loci in half-sib populations. Theor Appl Genet 1996, 93:71-80.
49. Moreno CR, Elsen JM, Le Roy P, Ducrocq V: Interval mapping methods for detecting QTL affecting survival and time-to-event phenotypes. Genet Res Camb 2005, 85:139-149.

50. Massault C, Bovenhuis H, de Koning DJ: QTL mapping designs for aquaculture. Aquaculture 2008, 285:23-29.

51. Bouza C, Sánchez L, Martínez P: Karyotypic characterisation of turbot (Scophthalmus maximus) with conventional fluorochrome and restriction endonuclease banding techniques. Mar Biol 1994, 120:609-613.

52. Imsland AK, Folkvord A, Grung GL, Stefansson SO, Taranger GL: Sexual dimorphism in growth and maturation of turbot, Scophthalmus maximus (Rafinesque, 1810). Aquaculture Research 1997, 28:101-114.

53. Cuesta A, Vargas-Chacoff L, García-López A, Arjona FJ, Martínez-Rodríguez G, Meseguer J, Mancera JM, Esteban MA: Effect of sex-steroid hormones, testosterone and estradiol, on humoral immune parameters of gilthead seabream. Fish \& Shellfish Immunology 2007, 23:693-700.

54. Peterson BC, Bosworth BG, Bilodeau AL: Differential expression of IGF-I, IGF-II, and toll-like receptors 3 and 5 mRNA during embryogenesis in hybrid (channel X blue) and channel catfish. Comparative Biochemistry and Physiology Part A 2005, 141:42-47.

55. Johansen K, Sealey W, Overturf KE: The effects of chronic immune stimulation on muscle growth in rainbow trout. Comparative Biochemistry and Physiology Part B 2006, 144:520-531.

56. Palti Y, Nichols KM, Waller Kl, Parsons JE, Thorgaard GH: Association between DNA polymorphisms tightly linked to MHC class II genes and IHN virus resistance in backcrosses of rainbow and cutthroat trout. Aquaculture 2001, 194:283-289.

57. Johnson NA, Vallejo RL, Silverstein JT, Welch TJ, Wiens GD, Hallerman EM, Palti Y: Suggestive association of major histocompatibility IB genetic markers with resistance to bacterial cold water disease in rainbow trout (Oncorhynchus mykiss). Mar Biotechnol 2008, 10:429-437.

58. Langefors A, Lohm J, Grahn M, Andersen O, von Schantz T: Association between major histocompatibility complex class IIB alleles and resistance to Aeromonas salmonicida in Atlantic salmon. Proc $R$ Soc Lond B Biol Sci 2001, 268:479-485.

59. Lohm J, Grahn M, Langefors Å, Andersen $\varnothing$, Storset A, von Schantz T: Experimental evidence for major histocompatibility complex allelespecific resistance to a bacterial infection. Proc R Soc Lond B Biol Sci 2002, 269:2029-2033.

60. Miller KM, Winton JR, Schulze AD, Purcell MK, Ming TJ: Major histocompatibility complex loci are associated with susceptibility of Atlantic salmon to infectious hematopoietic necrosis virus. Environ Biol Fishes 2004, 69:307-316.

61. Xu T, Chen S, Zhang Y: MHC class Ila gene polymorphism and its association with resistance/susceptibility to Vibrio anguillarum in Japanese flounder (Paralichthys olivaceus). Developmental \& Comparative Immunology 2010, 34:1042-1050.

62. Rakus KL, Wiegertjes GF, Adamek M, Siwicki AK, Lepa A, Irnazarow I: Resistance of common carp (Cyprinus carpio L.) to Cyprinid herpesvirus-3 is influenced by major histocompatibility $(\mathrm{MH})$ class II B gene polymorphism. Fish \& Shellfish Immunology 2009, 26:737-743.

63. Xu JY, Chen SL, Ding H: Specific MHC class II B alleles associated with resistance to Edwardsiella tarda in turbot, Psetta maxima (L.). J Fish Dis 2009, 32:637-640.

64. Turner SM, Faisal M, DeWoody JA: Zygosity at the major histocompatibility class IIB locus predicts susceptibility to Renibacterium salmoninarum in Atlantic salmon (Salmo salar L.). Animal Genetics 2007, 38:517-519.

65. Kongchum P, Sandel E, Lutzky S, Hallerman EM, Hulata G, David L, Palti Y: Association between IL-10a SNPs and resistance to Cyprinid herpesvirus-3 infection in common carp (Cyprinus carpio). Aquaculture 2011, 315:417-421.

66. Heng J, Su J, Huang T, Dong J, Chen L: The polymorphism and haplotype of TLR3 gene in grass carp (Ctenopharyngodon idella) and their associations with susceptibility/resistance to grass carp reovirus. Fish \& Shellfish Immunology 2011, 30:45-50.

67. Howarth DL, Law SHW, Barnes B, Hall JM, Hinton DE, Moore L, Maglich JM, Moore JT, Kullman SW: Paralogous vitamin D receptors in teleosts: transition of nuclear receptor function. Endocrinology 2008, 149:2411-2422.

68. Li LY, Shih HM, Liu MY, Chen JY: The cellular protein PRA1 modulates the anti-apoptotic activity of Epstein-Barr virus BHRF1, a homologue of Bcl- 
2, through direct interaction. The Journal of Biological Chemistry 2001, $276: 27354-27362$

69. Li J, Boroevich KA, Koop BF, Davidson WS: Comparative genomics identifies candidate genes for Infectious Salmon Anemia (ISA) resistance in Atlantic salmon (Salmo salar). Mar Biotechnol 2011, 13:232-241.

doi:10.1186/1471-2164-12-541

Cite this article as: Rodríguez-Ramilo et al:: QTL detection for Aeromonas salmonicida resistance related traits in turbot (Scophthalmus maximus). BMC Genomics 2011 12:541.

Submit your next manuscript to BioMed Central and take full advantage of:

- Convenient online submission

- Thorough peer review

- No space constraints or color figure charges

- Immediate publication on acceptance

- Inclusion in PubMed, CAS, Scopus and Google Scholar

- Research which is freely available for redistribution 